Communications in Physics, Vol. 24, No. 3S2 (2014), pp. 101-106

DOI:10.15625/0868-3166/24/3S2/5055

\title{
COLD ATMOSPHERIC PRESSURE GLIDING ARC PLASMA JET FOR DECONTAMINATION
}

\author{
DO HOANG TUNG \\ Institute of Physics, Vietnam Academy of Science and Technology \\ BACH SY MINH, VU THI THOM, AND LAM THI HUYEN TRANG \\ School of Medicine and Pharmacy, Vietnam National University, Hanoi \\ CAO THI HUONG \\ Thai Binh College of Education, Thai Binh, Vietnam \\ NGUYEN THI TUYEN \\ Hanoi Medical University \\ E-mail: dhtung@iop.vast.ac.vn \\ Received 04 April 2014 \\ Accepted for publication 24 May 2014
}

\begin{abstract}
A cold atmospheric pressure gliding arc plasma jet has been developed and applied to disinfection. The size of the plasma output is about $6 \mathrm{~mm}$ in diameter and $10 \mathrm{~mm}$ in length. Ar gas at a flow rate of 10 slm and $25 \mathrm{~W}$ plasma power are used. Plasma discharge is produced between the divergent electrodes and the jet appears as an effluence of the gas flow. When a pseudomonas culture is placed at $8 \mathrm{~mm}$ below the torch for 1minute, where the gas is at room temperature, the bacteria within a $16 \mathrm{~mm}$ diameter circle are almost completely killed. As the UV radiation is well below the safety regulation, the bacteria are inactivated by the total effect of $U V$ radiation and others like the reactive species and the charged particles.
\end{abstract}

Keywords: CAP; antimicrobial effect; gliding arc; wound healing.

\section{INTRODUCTION}

Physical plasma is a promising technology regarding its antimicrobial effects, especially in treatment of bacterial infected chronic wounds. Moreover, various plasma-based medical applications have been investigated with growing interest. Recently, research in atmospheric plasma sources has been quite active, as they have many advantages, e.g. low cost, simple design and easy handling [1]. These plasmas provide many chemical reactions at room-temperature and at atmospheric pressure due to the presence of high energy electrons. These discharges can be utilized for the cleaning of medical equipment $[2,3]$. In addition, they are able to treat substances which are not compatible with high vacuum, such as living organisms [4-18]. A contact-free treatment can be achieved without any harm of heat and pain.

(C)2014 Vietnam Academy of Science and Technology 

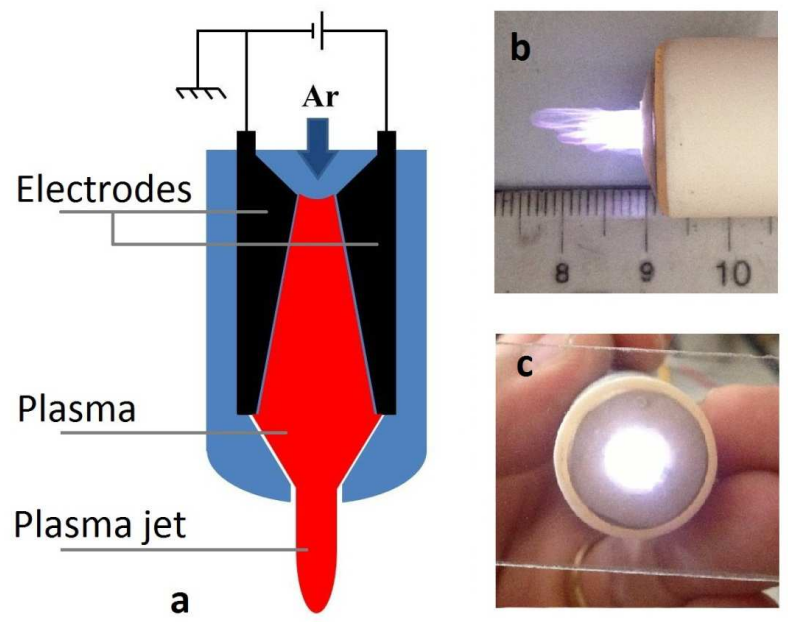

Fig. 1. Schematic view of the GA-CAP jet system: a) plasma torch system, b) side view of the plasma jet at $0.5 \mathrm{~s}$ exposure time, c) front view of the plasma jet on a glass slide 8 $\mathrm{mm}$ away from the torch nozzle (the exposure time is $10 \mathrm{~s}$ ).

In our group, a new atmospheric pressure plasma device, called - cold atmospheric pressure gliding arc plasma jet (GA-CAP Jet), has been developed and tested in order to examine the possibility of plasma therapy for chronic wounds. In this article, basic device characteristics and measurements of plasma effects on bacteria cultures are discussed.

\section{EXPERIMENTAL SETUP}

\section{Plasma apparatus}

A detailed view of the plasma torch is shown in Fig. 1(a). The plasma torch consists of 2 divergent stainless steel blade like electrodes placed inside a dielectric funnel. The plasma is ignited at the shortest distance $(2 \mathrm{~mm})$ between the two electrodes begins the cycle of the gliding arc evolution. The gas flow pushes the plasma column with the velocity of about $10 \mathrm{~m} \mathrm{~s}^{-1}$. The length of the arc increases with the voltage. When the length of the gliding arc exceeds its critical value, the non-equilibrium stage begins, and the plasma then rapidly cools down to room temperature while conductivity is sustained by high electron temperature. After decay of the non-equilibrium discharge, a new breakdown takes place at the shortest distance between the electrodes and the cycle repeats.

Through various designs, it was found that this geometric configuration gave the coolest GA-CAP jet for a given input power. Working under gliding arc principle, blade-like structure of the electrodes and the funnel plasma chamber are important for the triggering and stability of the discharge. The tips of the electrodes are situated at $10 \mathrm{~mm}$ to the nozzle. Since the typical size of chronic wounds is relatively large, our torch's opening is also made as wide as possible $(6 \mathrm{~mm}$ in diameter). In order to minimize toxic products during operation, only Ar gas (purity 99.99\%) was used to produce the plasma. 


\section{Measurement of plasma parameters}

The maximum temperature of the torch surface is $47^{\circ} \mathrm{C}$ during the experiments. Fig. 1(c) shows a front view of the plasma shape on a glass slide $8 \mathrm{~mm}$ under the torch (the exposure time of the photo is $10 \mathrm{~s}$ ). The shape of the plasma looks circular, although its shape is rather distorted in Fig. 1(b) where the exposure time is shorter. The gas temperature in the plasma flow below the torch was measured by a small thermocouples (type K). In order to assess the safety of the GA-CAP jet, a $z$-profile ( $z$ : distance from the torch's opening) of the UV light radiation power density was measured by a power meter (THB UV Power Meter UV340B) between 160 and 360 $\mathrm{nm}$.

\section{Pseudomonas culture on agar}

Pseudomonas aeruginosa SG81 was provided by Department of Microbiology of Hanoi Medical University. Pseudomonas aeruginosa SG81 was cultured on the base agar (Merck) with $10^{6}$ bacteria per $1 \mathrm{ml}$ using streak culture method. Bacteria was treated by plasma for $10 \mathrm{~s}, 30 \mathrm{~s}, 1$ min, 2 min, 3 min with 6 independent experiments each. The effects of plasma was quantified by the diameter of inhibition zone.

\section{RESULTS AND DISCUSSIONS}

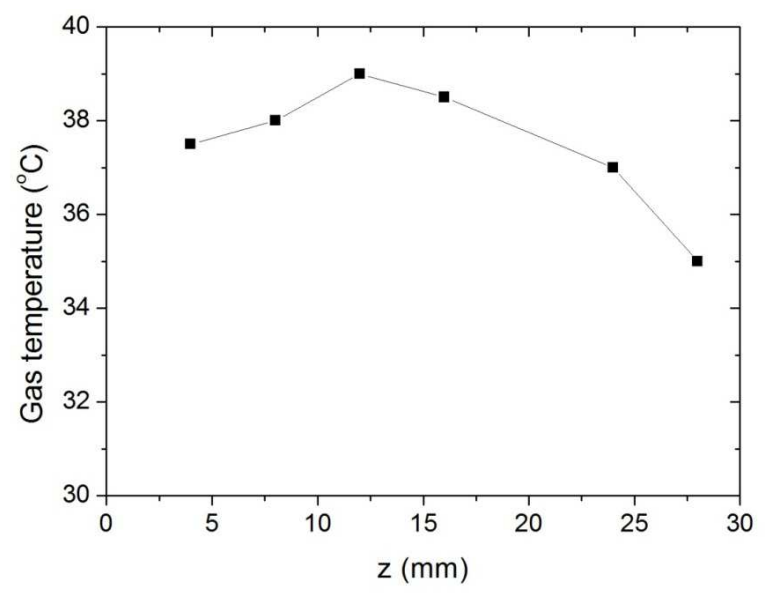

Fig. 2. Gas temperature as a function of the distance $z$ from the nozzle.

We investigated the axial profile of the gas temperature of the plasma jet. Room temperature was $30^{\circ} \mathrm{C}$. Fig. 2 shows the $z$-profiles of the measured gas temperature, along the jet axis. In the vicinity of the nozzle, the gas temperature is slightly rising outward to the maximum of $39^{\circ} \mathrm{C}$ at $z=12 \mathrm{~mm}$. Starting from $z=12 \mathrm{~mm}$, the gas temperature is decreased gradually. However at any position, the temperature is well below $40^{\circ} \mathrm{C}$, low enough for 'in vivo' application.

A typical UV radiation spectrum obtained from an Ar plasma jet contains two strong peaks in the UV-B region, and no strong line in the UV-C region. Fig. 3 shows a $z$-profile of the integrated UV power density. The sensor is placed at the center axis of the plasma jet. The UV power density decreases monotonically as $z$ increases. At the position where the samples are 
placed $(z=8 \mathrm{~mm})$, the UV power is $50 \mu \mathrm{W} / \mathrm{cm}^{2}$ well below the International Commission on Non-Ionizing Radiation Protection (ICNIRP) guideline for UV protection [19]. This means that our plasma jet is safe for 'in vivo' application in term of UV radiation.

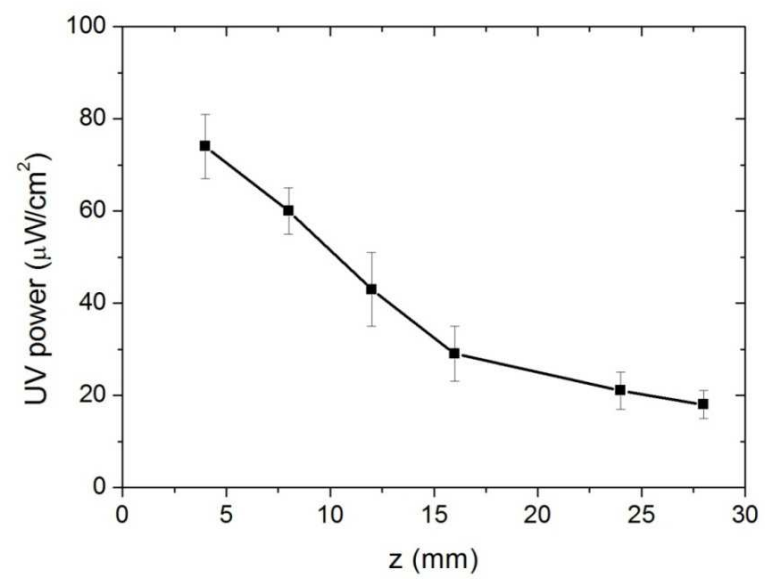

Fig. 3. UV power density measurements as a function of $z$.

In order to investigate the plasma exposure effect on bacteria, Pseudomonas aeruginosa $S G 81$ sample were placed $8 \mathrm{~mm}$ away from the output of the torch for 1 minute, 2 minutes, and 3 minutes. Clearly visible bactericidal effects can be observed as zone of inhibition zones on the agar plate (Fig. 4). The bacteria within circles of $16 \mathrm{~mm}, 20 \mathrm{~mm}$, and $23 \mathrm{~mm}$ diameters respectively, have been killed.

The boundary of the zones of inhibition was rather sharp, and the zones of inhibition were several times larger than the opening of the torch. The results on the diameters of the inhibition zones from 5 experiments are summarized and plotted in Fig. 5.

From our results, we can see that UV light could be one important agent for killing bacteria. However, it is possible other mechanisms related to charged particles [20] or reactive species [4,21] which are produced during the interaction of plasma with ambient air. This should be clarified in another study for mechanism of plasma effect on bacteria.

Diameter of the inhibition zone as a function of treatment time.

\section{CONCLUSION}

In conclusion, a cold atmospheric pressure gliding arc plasma jet has been developed for the purpose of "in vivo" bacterial disinfection. By using $10 \mathrm{slm}$ of Ar gas flow and $25 \mathrm{~W}$ of plasma power at atmospheric pressure, we obtained plasmas with characteristics which are suitable for medical applications and treatment.

Tests with cultures of Pseudomonas have proven the bactericidal effect. UV radiation was not the only agent responsible for killing bacteria; there are other mechanisms involved in sterilization of bacteria cultures. We consider that this technique can be used for a number of different medical applications, in particular healing wounds, and have started a clinical study for the therapy of chronic foot and leg ulcers. 


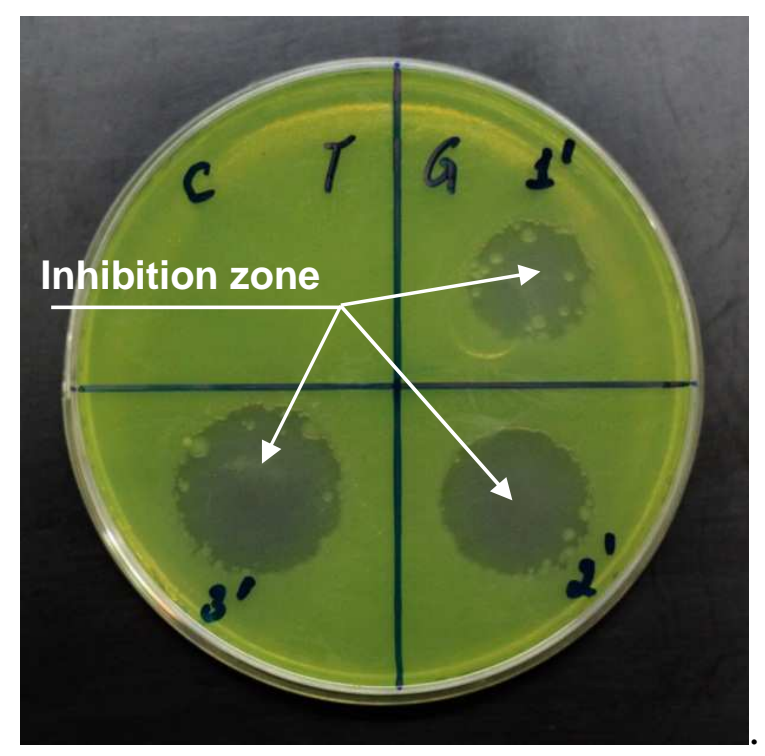

Fig. 4. Pseudomonas culture on an agar plate after plasma treatment for $1 \mathrm{~min}, 2 \mathrm{~min}$ and $3 \mathrm{~min}$. The culture was placed at $z=8 \mathrm{~mm}$, and the image was taken after 24 hours incubation.

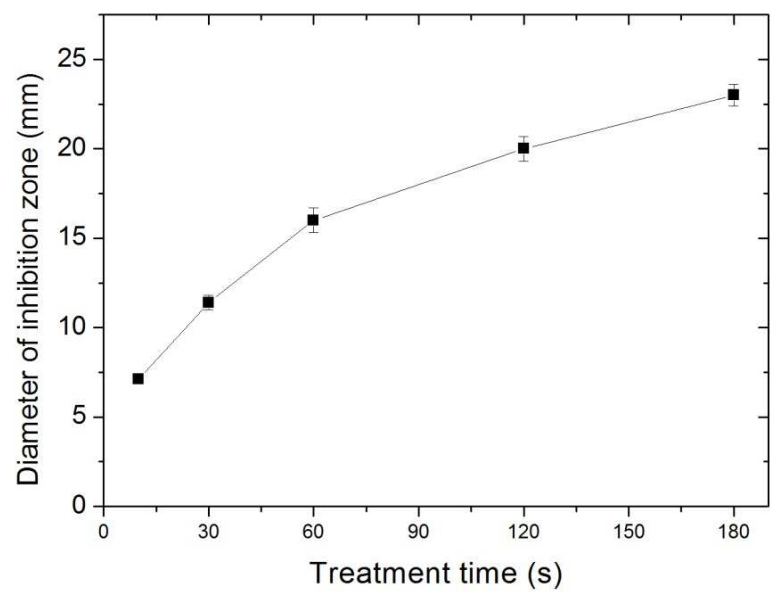

Fig. 5. Pseudomonas culture on an agar plate after plasma treatment for $1 \mathrm{~min}, 2 \mathrm{~min}$ and $3 \mathrm{~min}$. The culture was placed at $z=8 \mathrm{~mm}$, and the image was taken after 24 hours incubation.

\section{ACKNOWLEDGEMENTS}

This work was supported by the National Foundation for Science and Technology Development (NAFOSTED), Vietnam, under project number 103.05-2012.20 and Vietnam Plasma Technology Company Limited. Helpful discussions with Prof. Dr. Truong Viet Dung are gratefully acknowledged. 


\section{REFERENCES}

[1] J. Park, I. Henins, H. W. Hermann, G. S. Selwyn, R. F. Hicks, J. Appl. Phys. 89 (2001) 20.

[2] J. G. Birmmingham, D. J. Hammerstrom, IEEE Trans. Plasma Sci. 28200051.

[3] M. Laroussi, IEEE Trans. Plasma Sci. 30 (2002) 1409.

[4] T. C. Montie, K. Kelly-Wintenberg, J. R. Roth, IEEE Trans. Plasma Sci. 28 (2000) 41.

[5] K. Kelly-Wintenburg, D. M. Sherman, P. P.-Y. Tsai, R. B. Gardi, F. Karakaya, Z. Chen, J. R. Roth, T. C. Montie, IEEE Trans. Plasma Sci. 28 (2000) 64.

[6] E. Stoffels, A. J. Flikweert, W. W. Stoffels, G. M. W. Kroesen, Plasma Sources Sci. Technol. 11 (2002) 383.

[7] G. Fridman, A. Shereshevsky, M. M. Jost, A. D. Brooks, A. Fridman, A. Gutsol, V. Vasilets, G. Friedman, Plasma Chem. Plasma Process. 27 (2007) 163.

[8] G. Fridman, A. D. Brooks, M. Balasubramanian, A. Fridman, A. Gutsol, V. N. Vasilets, H. Ayan, and G. Friedman, Plasma Process. Polym. 4 (2007) 370.

[9] R. E. J. Sladek, E. Stoffels, R. Walraven, P. J. A. Tielbeek, R. A. Koolhoven, IEEE Trans. Plasma Sci. 32 (2004) 1540.

[10] M. Moisan, J. Barbeau, S. Moreau, J. Pelletier, M. Tabrizian, L. H. Yahia, Int. J. Pharm. 226 (2002) 1.

[11] B. J. Park, D. H. Lee, J.-C. Parka, I.-S. Lee, K.-Y. Lee, S. O. Hyun, M.-S. Chun, K.-H. Chung, Phys. Plasmas 10 (2003) 4539.

[12] T. Akitsu, H. Ohkawa, M. Tsuji, H. Kimura, M. Kogoma, Surf. Coat. Technol. 193 (2005) 29.

[13] M. Laroussi, X. Lu, Appl. Phys. Lett. 87 (2005) 113902.

[14] J. Goree, B. Liu, D. Drake, E. Stoffels, IEEE Trans. Plasma Sci. 34 (2006) 1317.

[15] T. Sato, T. Miyahara, A. Doi, S. Ochiai, T. Urayama, T. Nakatani, Appl. Phys. Lett. 89 (2006) 073902.

[16] X. T. Deng, J. J. Shi, G. Shama, M. G. Kong, Appl. Phys. Lett. 87 (2006) 153901.

[17] Q. S. Yu, C. Huang, F.-H. Hsieh, H. Huff, and Y. Duah, Appl. Phys. Lett. 88 (2006) 013903.

[18] E. Stoffels, Contrib. Plasma Phys. 1-2 (2007) 40.

[19] www.icnirp.de/documents/UV2004.pdf

[20] D. A. Mendis, M. Rosenberg, F. Azam, IEEE Trans. Plasma Sci. 28 (2000) 1304.

[21] M. Laroussi, D. A. Mendis, M. Rosenberg, New J . Phys. 5 (2003) 41. 